\title{
Foreword to the 50th Volume
}

\author{
Reto M. Hilty · Josef Drexl
}

Published online: 7 January 2019

(C) Max Planck Institute for Innovation and Competition, Munich 2019

Fifty years ago, shortly after the establishment of the Max Planck Institute for Foreign and International Patent, Copyright, and Competition Law in 1966, Eugen Ulmer as its founding director and Friedrich-Karl Beier, then assistant director, decided to launch IIC as a purely English-language journal on intellectual property law. IIC - at that time titled the "International Review of Industrial Property and Copyright Law" - was to supplement the already existing German-language journal GRUR Int., also managed by Ulmer and Beier as editors, yet in co-operation with the Deutsche Vereinigung für gewerblichen Rechtsschutz und Urheberrecht (GRUR).

The idea to expand into other regions of the world through a purely Englishlanguage journal, parallel to GRUR Int. in its orientation, proved to be a wise decision, which contributed enormously to the Institute's global visibility. In some regions - especially in Continental Europe and Asia - it was still common for IP lawyers to learn German and use it as a publication language. In the years to come, command of German became even more important for scholars who sought to excel in IP law, since it facilitated a research stay at the Max Planck Institute and, above all, a doctorate at the University of Munich under the supervision of one of the Institute's directors. Yet, given the very dynamic development of international IP law during that period and the growing belief that European IP rules would be needed in times of economic integration, it became essential to go beyond

\footnotetext{
R. M. Hilty $(\square)$

Director of the Max Planck Institute for Innovation and Competition, Full Professor (ad personam) at the University of Zurich, Honorary Professor at the Ludwig-Maximilians-Universität Munich, Munich, Germany

e-mail: hilty@ip.mpg.de

\section{J. Drexl}

Professor of Law; Director of the Max Planck Institute for Innovation and Competition, Honorary Professor at the Ludwig-Maximilians-Universität Munich, Munich, Germany e-mail: josef.drexl@ip.mpg.de
} 
enhancing scholarship among German speakers and to address the international community in English as the new lingua franca with the objective of influencing the future directions of scholarship in international and, soon to be, European IP law.

In terms of content, IIC initially focused on comparative law studies and the revisions of the IP Conventions, with the aim of expanding intellectual property protection. Yet, as early as the 1970s, IP scholars, not least from the Max Planck Institute, supported initiatives to establish more integrated European protection systems, with the European Patent Convention of 1973 as the most notable achievement. Moreover, IIC provided a platform for scholarly debate at a time when European harmonisation of national IP laws and the adoption of legislation on the first unitary protection systems gradually became a reality in the late 1980s. On the international level, the establishment of the WTO in 1994 and the adoption of the TRIPS Agreement exported standards previously accepted in the industrialised world to major emerging economies, such as India, China and Brazil, but also a large number of smaller and often less developed countries. At the same time, the criticism of these standards of protection, which were not necessarily in the interest of less developed economies, was quickly growing both in the recipient countries and among the global academic community.

These tensions are partly reflected in IIC's 25th anniversary special issue compiled by members of the Institute (see IIC 6/1995). The critical debates on international IP have continued ever since, with IIC becoming an important forum for the most diverse voices. In this journal, advocates of expanded protection as well as its critics had their say - provided that the scholarly quality and independence of a contribution were guaranteed.

Shortly after the reorientation and expansion of the Max Planck Institute in 2002, IIC was handed over to the two younger, newly appointed directors. As Editors-inChief, they expanded the journal's subject areas to include competition law, not only to reflect the broader fields of research at the Institute, but also to take into account the quickly growing importance of competition-related issues of intellectual property. Accordingly, the journal was renamed the "International Review of Intellectual Property and Competition Law". For the sake of quality management, the academic production of the journal was professionalised by transferring central tasks to a "legal manager". In 2013, IIC's publishing responsibility moved to the globally situated Springer group. A stringent peer-review system was instituted, which, thanks to a large, stable and extremely dedicated network of reviewers, guarantees the highest standards of quality control and impartiality. The journal's expansion to presently nine issues per year and the availability of its contents via internationally operating online providers has helped to spread the growing volume of current contents and to further promote the journal's standing as a globally leading scholarly medium in the areas of law it covers.

Looking to the future of these areas, the TRIPS Agreement will be much less likely to lead to further controversies, since from today's point of view - especially with regard to the needs of less developed countries - this set of rules has proven to be remarkably flexible and balanced. Instead, bilateral or plurilateral trade agreements nowadays cause much more concern. Often in the interest of individual 
industries, economies with strong bargaining power use such agreements to impose unbalanced TRIPS-plus standards on less developed countries.

This abandonment of multilateralism weighs all the more heavily as a considerable number of complex questions concerning the future await answers. The international community should develop these answers together in order to create a generally binding and sustainable regulatory framework, rather than focusing exclusively on national interests. In this context, the existence of recognised journals which are not oriented toward the short-term mainstream, but to taking up basic research topics with a long-term perspective, thereby providing a forum for independent academic analysis, is invaluable to ensure a balanced and competition-oriented IP system on the national, regional and international levels.

IIC feels more committed than ever to this mission. Its outstanding position in the fields of IP and competition law is due to its large and diverse authorship, and to a network from which IIC regularly receives important decisions originating from jurisdictions around the world.

The central questions for the future will only become visible gradually. The Max Planck Institute's task is to be at the forefront of identifying new issues and developments and keeping track of them. In this spirit, in the first issue of IIC's 50th volume, researchers from the Institute have undertaken to deepen some particularly topical challenges, which will also most likely figure highly among the Institute's research priorities in the next few years.

Finally, we would like to take this opportunity to thank our readers, authors, coeditors, peer reviewers as well as the publisher and the entire IIC team for their loyalty and dedication. We very much look forward to continuing our extremely fruitful cooperation with them. With their support, IIC is well prepared for the future!

Josef Drexl and Reto Hilty

Editors-in-Chief 